\title{
MULTIFOCAL SYNCHRONOUS SIGNET RING CELL CARCINOMA IN ULCERATIVE COLITIS- AN UNCOMMON PRESENTATION
}

\author{
Manjot Kaur ${ }^{1}$,Kanwaljit Kaur ${ }^{2}$
}

${ }_{1}^{1}$ Professor, Department of Surgery, Adesh Medical College. ${ }^{2}$ Assistant Professor, Department of Pathology, Fortis Hospital.

ABSTRACT
BACKGROUND
Ulcerative colitis is associated with an increased risk for developing colorectal cancer and precancerous dysplastic epithelial
changes. We present a case report of patient with ulcerative colitis of 22 years duration who presented with signet ring cell
carcinoma lesion at splenic flexure and adeno CA at anorectal junction and Linitis plastica of descending colon and paracolic
abscesses. Almost all the complications in one patient makes worthy of presentation.

\section{KEYWORDS}

IBD (Inflammatory Bowel Disease), PSC (Primary Sclerosing Cholangitis), Signet Ring Cell Carcinoma, Dysplasia, Adenocarcinoma, Linitis Plastica.

HOW TO CITE THIS ARTICLE: Kaur M, Kaur K. Multifocal synchronous signet ring cell carcinoma in ulcerative colitis- an uncommon presentation. J. Evolution Med. Dent. Sci. 2017;6(22):1831-1832, DOI: 10.14260/Jemds/2017/404

\section{BACKGROUND}

Colon is the state of third highest incidence of new malignancies and second only to lung cancer in mortality. The ulcerative colitis colorectal carcinoma link is well established. The factors that govern the risk of this most serious complication are duration of the disease and extend of involvement of the colon.

Incidence of colon cancers in patients with extensive ulcerative colitis is $5 \%-10 \%$ with disease duration of 20 years; $15 \%$ at 25 years and $30 \%$ at 35 years. Peak age of manifestation of ulcerative colitis is 20 - 40 years with no gender preponderance.[1] Chronic bowel infections, allergy to certain food articles, autoimmune factors, gender preponderance and emotional disturbances[2] are enlisted among various aetiological factors; $10 \%$ - 15\% of ulcerative colitis have a first degree relative with IBD. The extent of involvement of colon has a relation with occurrence of carcinoma colon.

Signet ring cell carcinoma has worse prognosis than mucinous adenocarcinoma. ${ }^{[3,4]}$ Mucinous and signet ring cell carcinoma are of much higher prevalence in patients with extensive ulcerative colitis than in general population.

\section{Case Report}

A 42-year-old male (Mohan Singh) with long history (22 years) of ulcerative colitis (diagnosed on biopsy) of ulcerative colitis on irregular treatment presented with septic shock. On examination he was severely anaemic, dehydrated and febrile. Abdomen was distended with generalised tenderness. On rectal examination, hard circumferential growth at anorectal junction was felt which was friable and bled on touch. Plain x-ray abdomen showed megacolon. Barium

Financial or Other, Competing Interest: None.

Submission 08-02-2017, Peer Review 04-03-2017,

Acceptance 10-03-2017, Published 16-03-2017.

Corresponding Author:

Manjot Kaur,

\#145, D-Block,

Ranjit Avenue,

Amritsar-143001, Punjab.

E-mail: manjot888@gmail.com

DOI: $10.14260 /$ jemds $/ 2017 / 404$ enema showed markedly distended caecum, ascending colon and transverse colon with delayed movement of contrast across splenic flexure, loss of haustrations in descending colon with strictures and acute narrowing in lower rectum. Biopsy of anorectal growth was taken, which was suggestive of adenocarcinoma.

Exploratory laparotomy revealed grossly dilated caecum, ascending colon and hepatic flexure with dense adhesions and pus pockets around splenic fixture. Descending colon was thick and tabular, sigmoid colon and rectum were collapsed. Liver was normal. Multiple significantly enlarged lymph nodes were present along the mesentery. Proctocolectomy with end ileostomy was done. Gross examination of specimen showed ulcerofungating growth $(8.5 \mathrm{~cm}$ to $6.5 \mathrm{~cm})$ at splenic flexure obstructing the lumen and another fungating growth at lower end rectum extending up to anorectal junction with multiple lymph nodes, which were reactive (Image 1).

Microscopic examination revealed that signet ring cell carcinoma at splenic fixtures with linitis plastica of descending colon, while growth at anorectal region was adenocarcinoma (Image 2 and 3 ).

Post-operative recovery was uneventful. Health of the patient improved remarkably, 2 years followup uneventful.

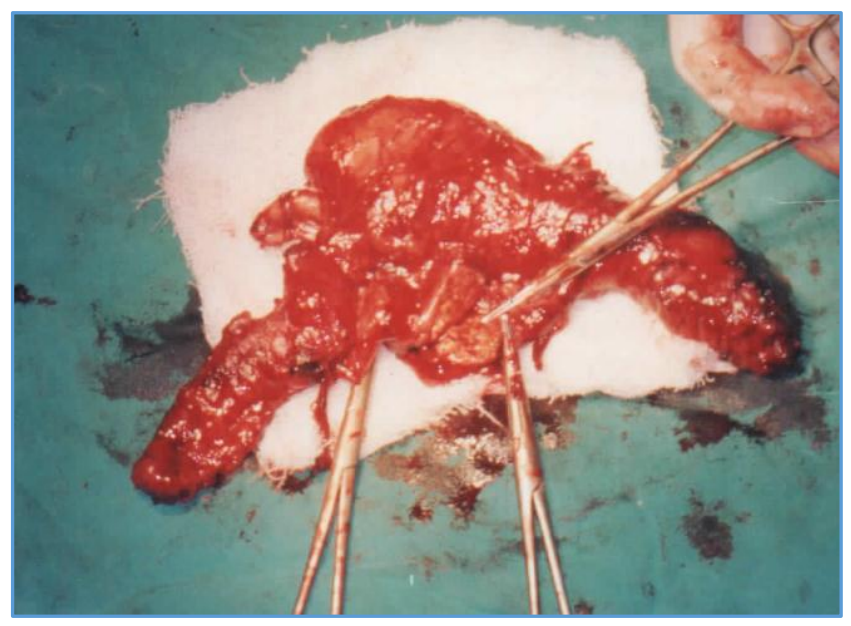

Image 1 


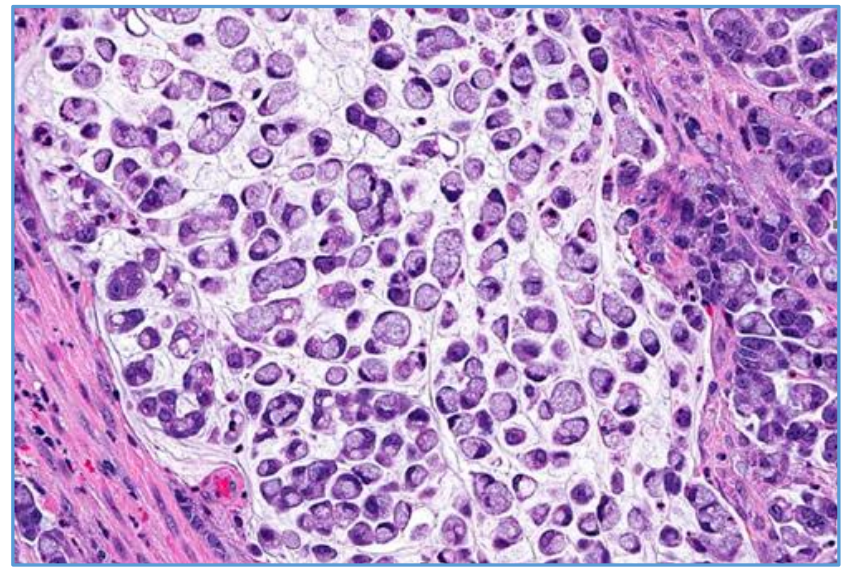

Image 2. Signet ring carcinoma (10X)

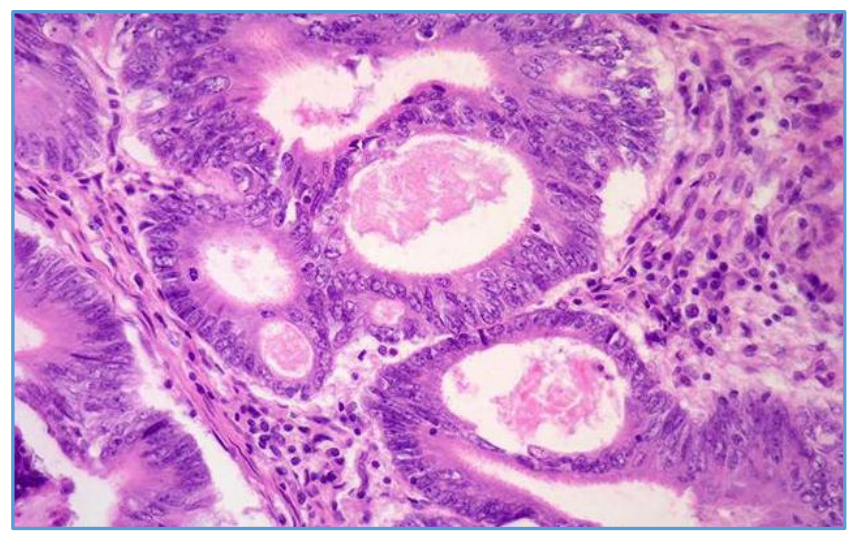

Image 3. Adenocarcinoma (40X)

\section{DISCUSSION}

Colorectal carcinoma represents an important and dreaded complication of long-standing IBD. The overall incidence of neoplasia in patients with pancolitis is $1 \%$ per year after 10 years so that cumulative risk of cancer is $10 \%$ by 20 years duration of disease. [5] Various risk factors of colorectal cancer in ulcerative colitis are enlisted as anatomic extent of the disease, duration of disease, age at onset of disease, primary sclerosing cholangitis. Disease activity, chromosomal instability, microsatellite instability are well documented pathways of ulcerative colitis related colorectal cancer.[6,7] The cancer tends to be more advanced, because they are difficult to be detected at an early stage. Approximately, 35\% are Duke's C and D category lesions. Certain distinguishing features of colon cancer in ulcerative colitis is that it occurs at a younger age, is more anaplastic, arises from flat mucosa, infiltrates broadly and is more often synchronous. Because of the potential impact on life expectancy and quality of life, optimising strategies are being suggested to reduce the risk of developing colorectal cancer in patients with IBD. These include colonoscopic surveillance, chemoprevention and surgical prophylaxis.

\section{Colonoscopic Surveillance}

The goal of this program is to identify cancer on their precursors (dysplasia) at an early stage, in which they are curable. Surveillance colonoscopy has been recommended by the American Society of Gastrointestinal Endoscopy after seven years of disease in patients with pancolitis and after ten years of disease in left-sided colitis. Colonoscopy and biopsy for dysplasia should be performed every year.

\section{Chemoprophylaxis}

Aspirin and non-steroidal anti-inflammatory drugs (5aminosalicylates) may offer a chemoprotective effect. Several studies have reported a colorectal risk reduction in patients with IBD taking folate supplements.[8,9] Interestingly, the use of ursodiol has shown $74 \%$ reduction in risk of colorectal carcinoma in patients with PSC-ulcerative colitis.[10]

\section{Surgical Prophylaxis}

The most effective way of preventing colorectal cancer in ulcerative colitis patients is to carry out proctocolectomy once dysplasia has been identified, because the risk of cancer in presence of dysplasia is $30 \%$. Nowadays, ideal technique is sphincter conserving approach. But in our patient as there was growth at anorectal junction, so proctocolectomy with end ileostomy had to be carried out.

\section{REFERENCES}

[1] Yang H, Shohat, Rotter J. The genetics of inflammatory bowel disease. In: Mac Demott RP, Stenton WF, eds. Inflammatory bowel disease. New York, Elselvier 1992:17-51.

[2] Feldman F, Cantor D, Soll S, et al. Psychiatric study of a consecutive series of 34 patients with ulcerative colitis. British Med J 1967;3(5556):14-7.

[3] Ekbom A, Helmick C, Zack M, et al. Ulcerative Colitis and colorectal cancer: a population bases study. N Eng J Med 1990;323(18):1228-33.

[4] Greenstein AJ, Sachar DB, Pucillo A, et al. Cancer in universal and left sided ulcerative colitis: clinical and pathological features. Mt Senai J Med 1979;46(1):2532.

[5] Schwartz SI. Schwartz's principles of surgery. Vol. 2. 7th edn. McGraw-Hill 1998:1215-7.

[6] Krok KL, Lichtenstein GR. Risk factors for colo-rectal cancer in inflammatory bowel disease. Curr Opin Gastroentrol 2004;20(1):43-8.

[7] Pinczowski D, Ekbom A, Baron J, et al. Risk factors for colorectal cancer in patients with ulcerative colitis: a case control study. Gastroenterology 1994;107(1):117-120.

[8] Lashner BA, Heidenreich PA, Su GL, et al. Effect of folate supplementation on the incidence of dysplasia and cancer in chronic ulcerative colitis. A case-control study. Gastroenterology 1989;97(2):255-9.

[9] Bansal P, Sonnenberg A. Risk factors of colorectal cancer in inflammatory bowel disease. Am J Gastroenterology 1996;91(1):44-8.

[10] Soetikno RM, Lin OS, Heidenreich PA, et al. Increased risk of colorectal neoplasia in patients with primary sclerosing cholangitis and ulcerative colitis: a metaanalysis. Gastrointest Endosc 2002;56(1):48-54. 